\title{
CRENÇAS E CONCEÇÕES DE ESTUDANTES DE EDUCAÇÃO FÍSICA AO LONGO DA FORMAÇÃO INICIAL: ESTUDO NOS SETORES PÚBLICO E PRIVADO EM PORTUGAL
}

\author{
Alberto Aires Albuquerque, Instituto Superior da Maia - ISMAI, São Pedro de Avioso, Maia - \\ Portugal \\ Cláudia Maria Pinheiro, Instituto Superior da Maia - ISMAI, São Pedro de Avioso, Maia - \\ Portugal \\ Paula Fazendeiro Batista, Universidade do Porto - UP, Porto - Portugal
}

\section{RESUMO}

O principal propósito deste estudo foi procurar perceber se estudantes de Educação Física e Desporto dos setores público e privado em Portugal alteram as suas conceções acerca do que é um bom professor ao longo da sua Formação Inicial. Adicionalmente procurou-se detetar qual o papel do Professor Cooperante neste processo. O estudo incorporou uma componente longitudinal, em que participaram 296 estudantes aos quais foi aplicado um questionário, em 3 anos momentos distintos do curso e uma componente transversal em que o corpus do estudo foi o relatório final de estágio de 90 estagiários. Os procedimentos de análise utilizados foram as medidas descritivas básicas para as questões fechadas do questionário e a análise de conteúdo para a questão aberta e relatórios de estágio. Os resultados indicaram que ocorreram transformações das conceções dos estudantes acerca do que é um bom professor, passando de uma valorização dos aspetos de natureza ética e relacional, para os de natureza técnica. Em termos do Professor Cooperante este emergiu como uma figura central ao processo formativo dos estagiários (último ano do curso), sendo-lhe atribuído os papéis de apoio e de orientação. As diferenças entre os estudantes do setor público e privado não foram relevantes.

Palavras-Chave: Formação inicial; Educação Física; Conceções; Professor competente; Professor cooperante.

\section{BELIEFS AND CONCEPTIONS OF STUDENTS PHYSICAL EDUCATION ALONG THEIR EDUCATIONAL PROGRAMME: A STUDY IN THE PUBLIC AND PRIVATE SECTORS IN PORTUGAL}

\begin{abstract}
The main purpose of this study was to understand if students of Physical Education and Sport of the public and private sectors in Portugal chance their conceptions about what is a good teacher during their educational program. Additionally we tried to detect the role of the Cooperating Teacher in this process. The study incorporated a longitudinal component, which was attended by 296 students to whom was applied a questionnaire in 3 different years of the course and a transversal one wherein the corpus of the study was the practicum final report of 90 pre-service teachers. The analysis procedures used were basic descriptive measures for the closed questions of the questionnaire and content analysis for open question and practicum final reports. The results indicated transformations of the students conception about what is a Conexões: revista da Faculdade de Educação Física da UNICAMP, Campinas, v. 11, n. 2, p. 127-147, abr./jun. 2013.127 ISSN: 1983-9030
\end{abstract}


good teacher, from an appreciation of the ethical aspects and relational to the technical appreciation. In terms of the Cooperating Teacher he emerged as a central figure in the preservice teachers training process of interns (final year of the training program), and assigned the roles of support and guidance. The differences between students of public and private sector were not relevant.

Key-Words: Initial training; Physical Education; Conceptions; Cooperating teacher; Competent teacher.

\section{CREENCIAS DE LOS ESTUDIANTES DE EDUCACIÓN FÍSICA A LO LARGO DE LA FORMACIÓN INICIAL: ESTUDIO EN LOS SECTORES PÚBLICO Y PRIVADO EN PORTUGAL}

\section{RESUMEN}

El propósito principal de este estudio fue conocer si los estudiantes de educación física y deporte de los sectores público y privado en Portugal alterarán sus creencias acerca de lo que es un buen profesor a lo largo de su formación inicial. Además se procuró detectar cuál es el papel del profesor cooperante en este proceso. El estudio incorpora un componente longitudinal, en que participaron 296 estudiantes a los que se aplicó un cuestionario, en momentos diferentes de 3 años del curso y un componente transversal en el que el corpus del estudio fue el informe final de prácticas de 90 alumnos. Los Procedimientos de análisis utilizados fueron las medidas descriptivas básicas para las preguntas cerradas del cuestionario y el análisis del contenido de la pregunta abierta e informes de final de prácticas. Los resultados indicaron que hubo transformaciones en las creencias de los estudiantes sobre lo que es un buen maestro, de una apreciación de los aspectos éticos y relacionales para los de carácter técnico. En términos del profesor cooperante esto surgió como figura central al proceso formativo de los alumnos (ultimo ano del curso), asignándose el papel de apoyo y orientación. Las diferencias entre los estudiantes del sector público y privado no fueron relevantes.

Palabras-Clave: Formación Inicial; Educación Física; Creencias; Profesor competente; Profesor cooperante 


\section{INTRODUÇÃO}

A aprendizagem da profissão docente é referida pela literatura como sendo o resultado de um conjunto de vivências que ultrapassam, em muito, a formação académica formal. Neste enquadramento, Flores e Day ${ }^{1}$ defendem que o percurso de vida de cada indivíduo representa uma parte importante no modo como cada um assume e efetiva a sua profissão.

No que concerne especificamente à profissão docente, as experiências como aluno (socialização antecipatória) são apontadas como muito relevantes no processo de socialização para a profissão. Com efeito, estas vivências experienciadas no papel de aluno, para além de contribuírem para a formação de conceções acerca do que é ensinar e aprender, condicionam o modo como o futuro profissional atribui significado às experiências tidas durante os programas de Formação Inicial (FI) ${ }^{2}$. Outro fator também amplamente referido como importante no processo de socialização do professor é o momento de transição da universidade para a vida profissional, mais especificamente ao nível do estágio profissional. ${ }^{3,4,5,6,7,8}$ Esta fase é usualmente marcada pelas dificuldades de articulação entre as perspetivas e as prioridades de conhecimento e as ações transmitidas na universidade e as veiculadas pelos professores nas escolas, designadamente pelo professor cooperante (PC), que assume a função de orientar os estudantes (estagiários) no processo de inserção na atividade profissional. ${ }^{9} \mathrm{Na}$ verdade, as perceções que usualmente acontecem apontam para uma noção que oconhecimento transmitido na universidade é irrelevante ou desfasado das necessidades da prática. A força socializadora destas mensagens veiculadas pelos intervenientes, concorre, em muitos casos, para a desvalorização das conceções transmitidas na FI, conduzindo ao designado de "washout effect"1 10,11 Neste enquadramento, e de modo a minimizar este efeito, reconhece-se que a necessidade de efetuar a transposição do conhecimento para a prática, pela sua natureza complexa e dinâmica, requerer uma interação com outros tipos de conhecimento, ${ }^{12}$ de forma a minimizar o choque com a realidade. ${ }^{4,5,10}$ A discrepância entre a necessidade de, por um lado, lidar com o imediato e, por outro, perceber a dinâmica teoriaprática-teoria, com inesperado desajustamento das expectativas e das imagens de professor ou da sua relação com os alunos, coloca o desafio de adaptação numa fasquia muito elevada. Este choque, quando não orientado, pode resultar numa experiência traumática, com consequências nefastas para o processo de desenvolvimento profissional. É, assim, neste contexto,que

\footnotetext{
${ }^{1}$ Efeito de lavagem (nossa tradução)

Conexões: revista da Faculdade de Educação Física da UNICAMP, Campinas, v. 11, n. 2, p. 127-147, abr./jun. 2013. ISSN: 1983-9030
} 
emerge um elemento crucial, o Professor Cooperante (PC), que aaume um papel fundamental auxiliando o estagiário neste processo de impactação com a realidade do ensino, ajudando-o a desenvolver competências para lidar com o contexto profissional, evitando, assim, o insucesso e abandono profissional. Pois, como refere Schön, ${ }^{13}$ as situações que um professor em formação enfrenta em certas situações da prática são únicas, incertas e conflituosas, pelo que carecem de enquadramento adequado.

Partindo destas premissas, e reconhecendo a importância do quadro de paradigmas que sustentam os pensamentos intersubjetivos e reflexivos acerca do professor de Educação Física (EF) e dos estudantes, ${ }^{14}$ neste estudo procurou-se acompanhar os estudantes ao longo da sua formação inicial (em 3 momentos distintos $-1^{\circ}$ e $3^{\circ}$ da licenciatura e $2^{\circ}$ ano do Mestrado em Ensino da Educação Física, materializado no Estágio Profissional), e, paralelamente indagar as conceções de Estudantes Estagiários (EEs) acerca das caraterísticas pessoais, formas de apoio instrucional e pessoais fornecidas e as dimensões de ensino que são privilegiadas pelos PCs, ${ }^{9}$ ao longo do mesmo ciclo temporal, mas com intervenientes distintos. Assim, foram definidos os seguintes objetivos centrais: (1) indagar se os estudantes de Educação Física e Desporto alteram as suas conceções ao longo da sua FI; e (2) identificar as características que os estudantes estagiários atribuem aos professores cooperantes. Adicionalmente foram ainda definidos os seguintes objetivos específicos:

- Caracterizar a socialização antecipatória dos estudantes que ingressam no curso de Educação Física e Desporto traduzida nas experiências positivas e negativas tidas como aluno de Educação Física nos níveis de ensino prévios à Formação Inicial;

- Identificar as caraterísticas, que no momento de entrada para a Formação Inicial, os estudantes atribuem como mais relevantes ao professor de Educação Física;

- Analisar a noção de "bom professor de Educação Física ao longo do percurso formativo dos estudantes (três momentos: $1^{\circ}$ e $3^{\circ}$ anos da licenciatura e $2^{\circ}$ ano do Mestrado em Ensino da Educação Física - ano do estágio)

- Verificar se os estudantes dos setores público e privado apresentam conceções diferenciadas à medida que o curso vai decorrendo (nos 3 momentos do estudo). 


\section{MATERIAL E MÉTODOS}

\section{Participantes}

Na persecução do propósito de incluir estudantes do ensino público e privado, os participantes foram de duas instituições diferenciadas, mas ambas da zona norte de Portugal. No cumprimento dos objetivos do estudo, o grupo de participantes da componente longitudinal do estudo foi constituído por 296 estudantes do $1^{\text {o }}$ ano do ano letivo 2007/2008, que teve uma redução natural nos momentos seguintes - 195 no $3^{\circ}$ ano e 122 no $2^{\circ}$ ano do mestrado em ensino da Educação Física. No que concerne à componente transversal do estudo, no ano letivo 2007/2008 foi constituído por 90 estagiários e 30 de cada um dos anos letivos subsequentes (2009/2010 e 2011/2012). Em ambos os extratos, metade dos alunos frequentavam uma instituição pública. Em termos caraterizacionais é de referir que a média de idades à entrada da FI era de 19,28 anos no setor público e 19,62 anos no privado (QUADRO 1).

Quadro 1 - Quadro sinóptico dos participantes

\begin{tabular}{ccccc}
\hline Ano Letivo & \multicolumn{2}{c}{ Estudantes } & \multicolumn{2}{c}{ Estagiários } \\
\hline & Público & Privado & Público & Privado \\
$2007 / 08$ & 148 & 148 & 15 & 15 \\
$2009 / 10$ & 98 & 97 & 15 & 15 \\
$2011 / 12$ & 61 & 61 & 15 & 15 \\
\hline
\end{tabular}

\section{Procedimentos de recolha e de análise}

Para a recolha dos dados recorreu-se a um questionário adaptado de Carreiro da Costa et al., ${ }^{15}$ que inclui os seguintes blocos temáticos: i) vivências positivas e negativas enquanto aluno de EF; ii) características relevantes do professor de EF; iii) noção de "bom professor". Na análise das respostas dos dois primeiros temas (questões fechadas) utilizaram-se medidas descritivas básicas (média, desvio-padrão, frequências absolutas e relativas). De referir que esta componente do questionário não contém questões exclusivas, nem obrigatórias, pelo que o tratamento das respostas, não conduz as percentagens para 100\%. Já no tema relativo à noção de "bom professor" (questão aberta) utilizou-se a análise de conteúdo, com o auxílio do programa NVIVO10. As categorias foram definidas a priori com base nas dimensões da avaliação da aptidão profissional docente enunciadas por Formosinho: ${ }^{16}$ a) dimensão intelectual, subdividida em formação inicial, conhecimento e actualização; b) dimensão 
técnica, subdividida em saber fazer, domínio pedagógico, domínio das técnicas de ensino, eficiência, consistência, decisão e organização; c) dimensão moral, subdividida em responsabilidade, profissionalismo, dedicação, motivação, empatia e pedagogia; e d) dimensão relacional, subdividida em relação interpessoal e trabalho de equipa.

Para a segunda componente do trabalho, relativa às perceções dos EEs acerca do PC, o corpus do estudo foram os relatórios finais de estágio, que foram analisados respeitando os seguintes procedimentos analíticos:

(1) Transcrição verbatim dos parágrafos dos relatórios relacionados com o $\mathrm{PC}$;

(2) Introdução dos dados no programa de análise qualitativa de dados NVIVO10;

(3) Desenvolvimento e aplicação de uma grelha teoricamente informada por:

- Gold $^{17}$ no que concerne à análise dos tipos de apoio: a) instrucional subdividido em instrumental, informacional e feedback; b) pessoal subdividido em emocional, apreciativo e aconselhamento;

- Januário ${ }^{18}$ na definição das dimensões de ensino - instrução, gestão, disciplina, clima, planeamento, tendo sido adicionada por razões operativas a categoria conteúdo;

- Albuquerque, Graça e Januário ${ }^{9}$ na introdução das categorias papéis liderança, aconselhamento, crítica, reflexão, observação, integração, segurança, apoio, estímulo, diálogo, ensinamento e orientação - e caraterísticas - honestidade, amizade, compreensão, competência, justiça, confiança, exigência e disponibilidade;

(4) Procura e contabilização da presença/ausência de temas e padrões comuns nos excertos dos relatórios.

Os dados foram analisados com base nas técnicas de análise de conteúdo, privilegiando os procedimentos da análise temática ${ }^{19}$ e as estratégias de análise qualitativa de dados. 


\section{RESULTADOS E DISCUSSÃO}

\section{Socialização antecipatória}

A análise dos dados relativos às vivências em EF revelou que a maioria dos estudantes, aquando da frequência do primeiro ano (2007/08), enunciou mais experiências positivas que negativas (QUADRO 2), materializadas nas relações interpessoais (colegas e professores) e na possibilidade de praticar várias modalidades desportivas. Ao nível das experiências negativas não se verificou uma opinião tão consensual. Os estudantes do setor público apontaram mais as caraterísticas do professor (autoritário, severo, humilhador, ...) enquanto os estudantes do setor privado referiram as lesões e a falta de recursos de EF. Esta alusão a estes aspetos negativos pode estar associado à debilidade de infraestruturas e equipamento necessário à EF que ainda existia em muitas escolas do ensino secundário que na altura ainda caraterizava o parque escolar em Portugal.

Quadro 2 - Experiências positivas e negativas dos estudantes do $1^{\circ}$ ano enquanto alunos de EF do Ensino Secundário

\begin{tabular}{|c|c|c|c|c|}
\hline \multirow[t]{2}{*}{ Setor } & \multicolumn{2}{|c|}{ Público (\%) } & \multicolumn{2}{|c|}{ Privado (\%) } \\
\hline & Positivas & Negativas & Positivas & Negativas \\
\hline Caraterísticas do professor & 14,02 & 23,13 & 5,59 & 8,8 \\
\hline Relações interpessoais & 30,48 & 7,46 & 19,58 & 6,4 \\
\hline Aptidão física (melhoria/fraca) & $4,26($ & 4,47 & 11,88 & 0,8 \\
\hline Prática de modalidades & 26,21 & 8,20 & 18,18 & 4,8 \\
\hline Recursos de EF & 1,21 & 10,44 & 1,39 & 10,4 \\
\hline $\begin{array}{l}\text { Participação em atividades extra- } \\
\text { curriculares }\end{array}$ & 9,75 & ------ & 9,79 & ----- \\
\hline Curriculum EF & ------ & 5,22 & ------ & 2,4 \\
\hline Lesões & ------ & 9,70 & ------ & 16,8 \\
\hline
\end{tabular}

No que concerne às caraterísticas positivas do professor de EF a personalidade/atitude (amigo, divertido, simpático...) sobressai claramente nos estudantes de ambos os setores. Já nas caraterísticas negativas, os estudantes do setor público realçam os aspetos da personalidade/atitude dos professores, enquanto os do setor privado apontam sobretudo as questões da competência (QUADRO 3). 
Quadro 3 - Caraterísticas do professor de Educação Física significativas para os estudantes do $1^{\circ}$ ano

\begin{tabular}{ccccccc}
\hline Caraterísticas & \multicolumn{2}{c}{$\begin{array}{c}\text { Personalidade/Atitude } \\
(\%)\end{array}$} & \multicolumn{2}{c}{$\begin{array}{c}\text { Competência } \\
\text { pedagógica/científica } \\
(\boldsymbol{\%})\end{array}$} & \multicolumn{2}{c}{ Clima da aula (\%) } \\
\cline { 2 - 7 } Setor & Positivas & Negativas & Positivas & Negativas & Positivas & Negativas \\
\cline { 2 - 7 } & $\mathbf{4 6 , 8 8}$ & $\mathbf{4 3 , 5 3}$ & $\mathbf{2 3 , 7 3}$ & 34,22 & 26,11 & $\mathbf{1 2 , 5 0}$ \\
Público & 23,89 & 20,79 & $\mathbf{3 5 , 8 4}$ & $\mathbf{3 0 , 6 9}$ & 11,94 \\
\hline
\end{tabular}

É notório que, independentemente da instituição em que ingressaram, os estudantes associam o prazer nas aulas de EF às relações que estabelecem com os professores e os seus pares e, em contraponto, o desprazer surge determinado pelas caraterísticas menos "afáveis" do professor. Percebe-se, assim, que o professor amigo, compreensivo é preferido e impacta as experiências de pré-socialização na generalidade dos estudantes. Deste modo, importa que os programas de FI sejam concebidos, estruturados e realizados de forma a permitirem ao futuro professor rever o seu entendimento prévio, corrigir e completar esse entendimento inicial, clarificar os conceitos centrais e os conselhos e recomendações sobre como se pode e deve agir na praxis pedagógica. Pois, como advogam autores como Meinberg ${ }^{20}$ e Crum, ${ }^{3}$ as conceções construídas na formação inicial são usualmente restritas, porquanto a força socializadora das vivências anteriores e respetivas preconceções, inibem, em muito, a reconstrução de novos entendimentos e conceções.

Por outro lado, e atendendo ao veiculado por um conjunto de autores, ${ }^{21,22}$ a formação ao decorrer de transições ecológicas que ocorrem quando se é confrontado com a assunção de novos papéis, em diferentes contextos, e da interacção gerada com outros autores, deve procurar reconfigurar entendimentos pela desconstrução dos anteriores. Este processo, pressupõe envolvimento pessoal, auto implicação e interação associada à experiência de aprendizagem na ação. Nesta ordem de ideias, o conhecimento do pensamento do EE é um elemento que deve ser tido em conta no processo decisional relativo à organização do currículo da FI (mais especificamente do mestrado em ensino ${ }^{2}$ ).

\footnotetext{
${ }^{2}$ Em Portugal, a formação de professores (mestrado em ensino) culmina com a Prática de Ensino Supervisionada (Estágio Profissional), que acontece no $2^{\circ}$ ano do referido mestrado. No presente estudo, o tempo dedicado à PES pelas duas Instituições de Ensino Superior em foco é semelhante, correspondendo a 48 créditos na pública e 45 na privada.

Conexões: revista da Faculdade de Educação Física da UNICAMP, Campinas, v. 11, n. 2, p. 127-147, abr./jun. 2013.134 ISSN: 1983-9030
} 


\section{A noção de "bom professor"}

O questionamento dos estudantes acerca da noção de "bom professor" ocorreu em três momentos distintos ( $1^{\circ}$ ano, $3^{\circ}$ ano e $2^{\circ}$ ano do mestrado em ensino) do processo de formação. Na primeira etapa efetuou-se uma análise geral (QUADRO 4), tendo por base as dimensões enunciadas por Formosinho, ${ }^{16}$ e posteriormente passou-se a uma análise mais específica de cada uma das dimensões, em função das respetivas categorias (QUADRO 5, 6, 7).

\section{Dimensões de aptidão profissional do professor}

No Quadro 4 é visível que ao longo do processo formativo ocorreram alterações na noção de "bom professor". Aquando do primeiro ano os estudantes de ambos os setores valorizam mais a dimensão ética e no início dos outros dois momentos a dimensão técnica ganha relevância, embora as questões éticas subsistam nos estudantes do setor privado.

No que concerne à dimensão intelectual no início é muito desvalorizada nos estudantes do setor público, recuperando nas observações subsequentes de forma crescente do primeiro para o terceiro momento. Já no setor privado, as questões relacionadas com o conhecimento apenas são substanciais do $3^{\circ}$ ano para o ano de estágio. A valorização superior da dimensão ética no primeiro ano decresce ligeiramente, em contraponto a uma maior valorização das questões de natureza técnica, sendo que os estudantes do setor público também evidenciam uma maior valorização do conhecimento, o que não ocorria quando chegaram à Faculdade ( $1^{\circ}$ ano).

Quadro 4 - Representação das dimensões da competência na conceção de "bom professor" nos 3 momentos

\begin{tabular}{lcccccc}
\hline & Setor & \multicolumn{3}{c}{ Público (\%) } & \multicolumn{3}{c}{ Privado (\%) } \\
\cline { 2 - 7 } \multicolumn{1}{c}{ Dimensão } & $\mathbf{1}^{\mathbf{0}}$ ano & $\mathbf{3}^{\mathbf{0}}$ ano & PES & $\mathbf{1}^{\mathbf{0}}$ ano & $\mathbf{3}^{\mathbf{0}}$ ano & PES \\
\hline Intelectual & 8,48 & 23,40 & $\mathbf{4 4 , 2 4}$ & 10 & 12,50 & $\mathbf{2 3 , 4 5}$ \\
Técnica & 34,55 & $\mathbf{6 8 , 0 9}$ & $\mathbf{7 2 , 2 1}$ & 21,43 & $\mathbf{5 2 , 0 6}$ & $\mathbf{5 6 , 6 8}$ \\
Ética & $\mathbf{5 2 , 1 2}$ & 44,68 & 45,23 & $\mathbf{5 5 , 7 1}$ & 35,42 & 33,25 \\
Relacional & 4,85 & 6,38 & 5,07 & 12,86 & 1,04 & 3,07 \\
\hline
\end{tabular}

\section{Dimensão Intelectual}

A valorização atribuída pelos estudantes do $1^{\circ}$ ano à subcategoria conhecimento, acentua-se no terceiro ano e no ano da PES. Nas palavras sobejam deles, expressões como "conhecimento da matéria de ensino" e "conhecimentos da área". 
No Quadro 5 pode observar-se o decréscimo da importância da subcategoria formação inicial do primeiro para o terceiro ano. Este dado, é, no mínimo, curioso, pois, aparentemente os estudantes não reconhecem valor aos três primeiros anos de formação para a futura função como futuros professores. A explicação talvez esteja no facto de os três primeiros anos de formação terem uma a forte componente prática, muito direcionada para a eficiência e para o rendimento, o que pode dificultar a apreensão do valor formativo do currículo para o aprender a ensinar, mais relacionado com os aspetos pedagógico-didáticos. Este aspeto inverte-se nos anos subsequentes, facto que talvez encontre explicação na estrutura curricular, mais direcionada para as áreas pedagógicas e didáticas, designadamente com o estágio em contexto real de ensino, que ocorre no segundo ano do mestrado. Outro dado que sobreveio é a pouca valorização da noção de investimento na formação contínua.

Quadro 5 - Representação da dimensão intelectual na conceção de "bom professor" nos 3 momentos

\begin{tabular}{lccccccc}
\hline & Setor & \multicolumn{3}{c}{ Público (\%) } & \multicolumn{3}{c}{ Privado (\%) } \\
\cline { 2 - 7 } Dimensão & $\mathbf{1}^{\mathbf{0}}$ ano & $\mathbf{3}^{\mathbf{0}}$ ano & PES & $\mathbf{1}^{\mathbf{0}}$ ano & $\mathbf{3}^{\mathbf{0}}$ ano & PES \\
\cline { 2 - 7 } Formação inicial & 21,43 & 12,34 & 33,44 & 28,57 & 8,33 & 30.22 \\
Conhecimento & $\mathbf{7 1 , 4 3}$ & $\mathbf{9 0 , 9 1}$ & $\mathbf{9 2 , 2 1}$ & $\mathbf{7 1 , 4 3}$ & $\mathbf{7 5}$ & $\mathbf{8 0 , 2 0}$ \\
Formação contínua & 7,14 & 9,10 & 12,35 & & 16,67 & 15,50 \\
\hline
\end{tabular}

\section{Dimensão Técnica}

A subcategoria técnicas de ensino mantem sempre um nível elevado. As questões do saber fazer, usualmente associadas ao professor de EF, tendem a prevalecer nas conceções dos estudantes ao longo da sua FI. Esta valorização superior do saber fazer comparativamente ao domínio pedagógico, contraria os referenciais teóricos que apontam para uma maior importância do domínio pedagógico, no que concerne ao entendimento de "bom professor". Parece, portanto, que pode haver alguma confusão entre os conceitos de "pedagogia" e "saber fazer". A subcategoria eficiência/qualidade surge com uma valorização crescente, sendo que na PES é a mais valorizada pelos alunos do setor público. As restantes subcategorias apresentam valores meramente residuais (QUADRO 6). 
Quadro 6 - Representação da dimensão técnica na conceção de "bom professor" nos 3 momentos

\begin{tabular}{lcccccc}
\hline & Setor & \multicolumn{3}{c}{ Público (\%) } & \multicolumn{3}{c}{ Privado (\%) } \\
\cline { 2 - 7 } Dimensão técnica & $\mathbf{1}^{\mathbf{0}}$ ano & $\mathbf{3}^{\mathbf{0}}$ ano & PES & $\mathbf{1}^{\mathbf{0}}$ ano & $\mathbf{3}^{\mathbf{0}}$ ano & PES \\
\hline Saber fazer/aplicar & 3,67 & 5,26 & 5,28 & & 11,87 & 12,23 \\
Pedagogia & $\mathbf{2 5 , 5 8}$ & $\mathbf{2 3 , 6 8}$ & 29,24 & $\mathbf{2 9 , 1 7}$ & 11,87 & 15,56 \\
Técnicas de ensino & $\mathbf{5 3 , 4 9}$ & $\mathbf{4 7 , 3 7}$ & $\mathbf{3 4 , 2 4}$ & $\mathbf{6 2 , 5}$ & $\mathbf{4 7 , 4 6}$ & $\mathbf{3 4 , 4 5}$ \\
Eficiência/qualidade & 4,65 & 15,79 & $\mathbf{3 5 , 5 6}$ & - & $\mathbf{1 3 , 5 6}$ & $\mathbf{2 3 , 4 5}$ \\
Consistência/flexibilidade & 6,98 & 2,63 & 2,36 & - & 8,47 & 7,56 \\
Decisão/inovação & 6,98 & 2,63 & 2,45 & 8,33 & 1,70 & 1,76 \\
Método & & 2,63 & 2,33 & & 5,08 & 5,28 \\
\hline
\end{tabular}

\section{Dimensão Ética}

O bom senso/empatia e pedagogia são as subcategorias mais importantes da dimensão ética à entrada; o profissionalismo, no setor privado, assume a mesma importância da pedagogia e no público aparece $\operatorname{logo}$ a seguir à pedagogia. No outro extremo situam-se as subcategorias autoridade/maturidade/experiência e dedicação/envolvimento apresentam valores residuais; também aqui há concordância entre os dois setores. Com a progressão da formação constatouse que o profissionalismo passa a assumir-se como a subcategoria mais relevante e o bom senso/empatia decresce para valores insignificantes. Já a pedagogia passa a ser a segunda subcategoria mais valorizada. É notória a tónica nas questões profissionais em detrimento das questões do saber estar, com as questões pedagógicas sempre importantes. Nesta dimensão as expressões mais referidas além do profissionalismo são: "professor amigo, atento" e "gosta do que faz" (QUADRO 7).

Quadro 7 - Representação da dimensão ética na conceção de "bom professor" nos 3 momentos

\begin{tabular}{|c|c|c|c|c|c|c|}
\hline \multirow[b]{2}{*}{ Dimensão ética } & \multicolumn{3}{|c|}{ Público (\%) } & \multicolumn{3}{|c|}{ Privado (\%) } \\
\hline & $1^{\circ}$ ano & $3^{\circ}$ ano & PES & $1^{\circ}$ ano & $3^{\circ}$ ano & PES \\
\hline Responsabilidade/deontologia & 10,47 & 3,70 & & 15,38 & 15 & 11,20 \\
\hline Profissionalismo & 19,77 & $\mathbf{5 1 , 8 5}$ & 56.56 & 25,64 & 32,50 & 36,55 \\
\hline Dedicação/envolvimento & 2,33 & 3,70 & 1,88 & & 5 & 4,68 \\
\hline Motivação intrínseca & 10,47 & 11,11 & 7,34 & 5,13 & 17,50 & 16,58 \\
\hline Bom senso/empatia & 29,07 & & 2,77 & 25,64 & 2,50 & 1,47 \\
\hline Pedagogia & 27,91 & 29,62 & 29,34 & 28,21 & 25 & 26,88 \\
\hline Autoridade/maturidade/experiência & 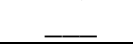 & , & 2,34 & & 2,5 & 2,56 \\
\hline
\end{tabular}

\section{Dimensão Relacional}

De novo uma semelhança entre os estudantes dos dois setores (QUADRO 8). Não atribuir relevância ao trabalho de equipa nos dois primeiros momentos levanta a necessidade de 
perceber a razão. No final surge a valorização do trabalho em equipa em ambos os setores, embora os do setor público lhe atribuam uma importância superior (25,67\% contra 19,87\%).

O facto de a PES ocorrer em núcleos constituídos por três ou quatro elementos pode reforçar a necessidade de trabalhar em equipa; contudo não deixa de alertar para a necessidade de proceder a alterações formativas pois essa é uma competência transversal.

Quadro 8 - Representação da dimensão relacional na conceção de "bom professor" nos 3 momentos

\begin{tabular}{lcccccc}
\hline & Setor & \multicolumn{3}{c}{ Público (\%) } & \multicolumn{3}{c}{ Privado (\%) } \\
\cline { 2 - 7 } Dimensão & $\mathbf{1}^{\mathbf{0}}$ ano & $\mathbf{3}^{\mathbf{0}}$ ano & PES & $\mathbf{1}^{\mathbf{0}}$ ano & $\mathbf{3}^{\mathbf{0}}$ ano & PES \\
\hline Relações interpessoais & 100 & 100 & & 100 & 100 & \\
Trabalho de equipa & 0 & 0 & 25,67 & 0 & 0 & 19,87 \\
\hline
\end{tabular}

\section{Percepção dos Estudantes Estagiários Acerca dos Professores Cooperantes}

\section{Papéis e caraterísticas dos PCs}

No Quadro 9 figuram os dez papéis para os quais os EEs remetem os PCs. Apoio e orientação são os mais valorizados em ambos os setores e a integração surge entre os 3 tipos de apoio mais valorizados.

Curiosamente, ensinamento e reflexão aparecem com pouca expressão nos momentos iniciais, apesar da recuperação no terceiro momento (público - 13,3\% e privado - 16,3\%). A ordem de valorização dos diferentes tipos de papéis não sofreu alterações significativas ao longo dos anos deste estudo; contudo, é notória uma mudança na tipologia das valorizações no último momento com maior relevância da generalidade do número de referências e valorização das subcategorias estímulo, crítica, ensinamento, reflexão e orientação.

Diálogo e observação não apresentaram qualquer expressão nos dois primeiros momentos do sector privado, mas valorizam-se consideravelmente no último momento. Estes estudantes também atribuíram um valor considerável ao papel de aconselhamento, ao passo que os do setor público só o valorizam no final. A transformação da valorização nos alunos que foram acompanhados desde a entrada do curso até ao seu final é maior. 
Quadro 9 - Referências a papéis dos PCs nos relatórios de estágio dos EEs dos 3 anos letivos

\begin{tabular}{lcccccc}
\hline \multirow{2}{*}{ Setor } & \multicolumn{3}{c}{ Público (\%) } & \multicolumn{3}{c}{ Privado (\%) } \\
\cline { 2 - 7 } Papéis & $\mathbf{2 0 0 7 / 0 8}$ & $\mathbf{2 0 0 9 / 1 0}$ & $\mathbf{2 0 1 1 / 1 2}$ & $\mathbf{2 0 0 7 / 0 8}$ & $\mathbf{2 0 0 9 / 1 0}$ & $\mathbf{2 0 1 1 / 1 2}$ \\
\hline Apoio & $\mathbf{3 6 , 5}$ & $\mathbf{3 7 , 6}$ & $\mathbf{4 0 , 0}$ & $\mathbf{2 3 , 9}$ & $\mathbf{2 6 , 0}$ & $\mathbf{8 0 , 0}$ \\
Integração & $\mathbf{1 5 , 3}$ & $\mathbf{1 1 , 1}$ & 23,3 & 7,3 & - & 33,3 \\
Estímulo & $\mathbf{1 , 9}$ & $\mathbf{7 , 9}$ & 20,0 & $\overline{ }$ & - & 16,2 \\
Aconselhamento & $\overline{\mathbf{1 , 9}}$ & $\overline{\mathbf{4 , 5}}$ & 13,3 & 17,6 & $\mathbf{\mathbf { 2 1 , 0 }}$ & 23,3 \\
Crítica & $\mathbf{7 , 6}$ & $\mathbf{5 , 6}$ & 20,0 & $\mathbf{2 , 1}$ & $\mathbf{6 , 7}$ & 26,3 \\
Ensinamento & $\mathbf{3 , 1}$ & $\mathbf{6 , 2}$ & 30,0 \\
Reflexão & $\mathbf{1 , 9}$ & & 13,3 & $\mathbf{8 , 3}$ & - & 16,3 \\
Orientação & $\mathbf{7 , 6}$ & 10,2 & $\mathbf{4 6 , 3}$ & $\mathbf{2 8 , 1}$ & $\mathbf{9 , 1}$ & $\mathbf{9 0 , 0}$ \\
Diálogo & $\mathbf{9 , 1}$ & $\mathbf{9 , 3}$ & 13,3 & - & - & 13,3 \\
Observação & $\mathbf{9 , 2}$ & $\mathbf{9 , 2}$ & 13,3 & - & - & 13,3 \\
\hline
\end{tabular}

O Quadro 10 retrata os aspetos relativos aos comportamentos dos PCs que se relacionam com o processo de concretização das suas intenções educativas. Nesta dimensão, as caraterísticas mais valorizadas foram a amizade, a competência e a disponibilidade. Nos estudantes do setor público, a amizade logo seguida da competência, assumem a primazia, com exceção do último momento em que a caraterística mais relevante é a disponibilidade seguida da confiança. No setor privado valoriza-se mais a disponibilidade, colocando em segundo lugar a amizade, com exceção do terceiro momento em que a amizade é a mais valorizada, logo seguida da exigência. A exigência e a compreensão assumem fraca visibilidade nos dois primeiros momentos em ambos os setores, assim como a confiança no setor privado. Avaliam sobretudo a capacidade do PC lhes proporcionar ajuda, estar disponível e revelar segurança naquilo que faz.

Os EEs do ano 2011/12, de ambos os setores, revelaram uma valoração diferenciada em relação aos outros anos, contudo amizade e disponibilidade são as que ocupam o primeiro posto mais vezes.

Quadro 10 - Referências a caraterísticas dos PCs nos relatórios de estágio dos EEs dos 3 anos letivos

\begin{tabular}{lcccccc}
\hline \multicolumn{1}{c}{ Setor } & \multicolumn{3}{c}{ Público $(\%)$} & \multicolumn{3}{c}{ Privado $(\%)$} \\
Caraterísticas & $\mathbf{2 0 0 7 / 0 8}$ & $\mathbf{2 0 0 9 / 1 0}$ & $\mathbf{2 0 1 1 / 1 2}$ & $\mathbf{2 0 0 7 / 0 8}$ & $\mathbf{2 0 0 9 / 1 0}$ & $\mathbf{2 0 1 1 / 1 2}$ \\
Amizade & $\mathbf{7 4 , 7}$ & $\mathbf{7 4 , 6}$ & 23,3 & $\mathbf{2 0 , 0}$ & $\mathbf{2 1 , 5}$ & $\mathbf{5 0 , 0}$ \\
Competência & $\mathbf{2 4 , 6}$ & $\mathbf{2 4 , 5}$ & 16,3 & 17,5 & 19,6 & 30,0 \\
Confiança & - & 12 & $\mathbf{2 6 , 3}$ & 12,5 & 2,3 & 16,3 \\
Exigência & - & 3,4 & 10,0 & 7,5 & 7,8 & $\mathbf{4 3 , 3}$ \\
Disponibilidade & - & 6,7 & $\mathbf{4 0 , 0}$ & $\mathbf{2 7 , 5}$ & $\mathbf{2 7 , 6}$ & 33,3 \\
Compreensão & - & 8,6 & 16,3 & 7,5 & 7,3 & 20,0 \\
\hline
\end{tabular}


Tipos de apoio dos PCs

A análise revela que o apoio prestado pelos PCs foi importante no processo de formação dos EEs. Os aspetos emocional e apreciativo foram os mais relevantes nos três momentos e em ambos os setores (QUADRO 11). Contrariamente ao que se verificou nos Quadros 9 e 10, a imagem do Quadro 11 é constante, com a maior valorização do apoio emocional e menor valorização do aconselhamento. Esta regularidade nas valorizações talvez possa ser entendida pelo facto do ano da PES ser aquele em que o trabalho tem mais volume e é contínuo. $\mathrm{O}$ trabalho constante é algo a que os estudantes não estão habituados, porquanto nos anos anteriores o trabalho acontece por picos, concentrando-se nas épocas de frequências e exames. Com o incremento do trabalho e do seu ritmo, é natural que os apoios emocional e apreciativo sejam os que apresentam maior expressão. Como muitos dos EEs já trabalham, será natural que procurem suporte emocional nos PCs que com eles estão diariamente.

Os resultados mostram concordância com Anderson e Shannon, ${ }^{23}$ para quem o ato de orientar em educação deve obrigar o PC a: (1) estabelecer relações, assumindo o papel de modelo, de criador de situações e de protetor; (2) ser, portanto, professor, patrocinador, encorajador, conselheiro, amigo; (3) coordenar actividades, demonstrando lições, observando e emitindo feedbacks, dirigindo reuniões. Calderhead e Schorrock ${ }^{24}$ enumeram diversas formas que os PCs utilizam para influenciar os EEs: (1) pelo exemplo (modelo do próprio comportamento); (2) pelo treino (observação e discussão participada com prática repetida e estratégias particulares, objetivos e tipos de lições); (3) pela discussão da prática (conversando e discutindo sobre a prática); (4) pela estruturação do contexto (influência indirecta nas práticas que o EE pode adoptar num dado contexto); (5) pelo apoio emocional (apoio e encorajamento para solucionar problemas de inseguranças acerca do processo de ensino e aprendizagem); (6) pela invenção de experiências de ensino (construção de situações especiais para promover a aprendizagem dos EEs). 
Quadro 11 - Referências a tipos de apoio pessoal dos PCs nos relatórios de estágio dos EEs dos 3 anos letivos

\begin{tabular}{lcccccc}
\hline \multirow{2}{*}{$\begin{array}{c}\text { Setor } \\
\text { Apoio pessoal }\end{array}$} & \multicolumn{3}{c}{ Público (\%) } & \multicolumn{3}{c}{ Privado (\%) } \\
\cline { 2 - 7 } & $\mathbf{2 0 0 7 / 0 8}$ & $\mathbf{2 0 0 9 / 1 0}$ & $\mathbf{2 0 1 1 / 1 2}$ & $\mathbf{2 0 0 7 / 0 8}$ & $\mathbf{2 0 0 9 / 1 0}$ & $\mathbf{2 0 1 1 / 1 2}$ \\
\hline Emocional & 50,2 & 54,5 & $\mathbf{6 0 , 0}$ & 47,5 & 45,6 & $\mathbf{4 6 , 6}$ \\
Apreciativo & 23,4 & 23,2 & $\mathbf{3 3 , 3}$ & 34,2 & 35,6 & $\mathbf{4 0 , 0}$ \\
Aconselhamento & 12,3 & 11,3 & 13,3 & 10,3 & 11,2 & 13,3 \\
\hline
\end{tabular}

O apoio instrucional (QUADRO 12) mostra a ênfase no apoio instrumental, que incorpora todas as orientações relativas ao fazer pedagógico aquando do planeamento, execução e avaliação do processo de ensino e aprendizagem dos estagiários. Os alunos do setor privado dão maior destaque ao apoio instrumental em todos os momentos, assumindo a maior diferenciação no terceiro momento (privado - 73,3\%; público - 53,3\%). Os demais tipos de apoio revelam-se similares nos dois setores, sendo que o informacional ocupa o segundo lugar na ordem de importância.

Quadro 12 - Referências a tipos de apoio instrucional dos PCs nos relatórios de estágio dos EEs dos 3 anos letivos

\begin{tabular}{lcccccc}
\hline \multirow{1}{*}{ Setor } & \multicolumn{3}{c}{ Público (\%) } & \multicolumn{3}{c}{ Privado (\%) } \\
\cline { 2 - 7 } Apoio & $\mathbf{2 0 0 7 / 0 8}$ & $\mathbf{2 0 0 9 / 1 0}$ & $\mathbf{2 0 1 1 / 1 2}$ & $\mathbf{2 0 0 7 / 0 8}$ & $\mathbf{2 0 0 9 / 1 0}$ & $\mathbf{2 0 1 1 / 1 2}$ \\
instrucional & & & & & & \\
Instrumental & $\mathbf{4 5 , 6}$ & $\mathbf{4 6 , 7}$ & $\mathbf{5 3 , 3}$ & $\mathbf{6 5 , 4}$ & $\mathbf{6 9 , 6}$ & $\mathbf{7 3 , 3}$ \\
Informacional & 19,7 & 23,4 & 20,0 & 18,9 & 23,4 & 26,6 \\
Feedback & 12,3 & 11,2 & 13,3 & 8,9 & 5,6 & 6,6 \\
\hline
\end{tabular}

\section{Dimensões de ensino}

O planeamento e a instrução dada pelos PCs são as ações pedagógicas mais valorizadas em ambos os setores de ensino (QUADRO 13), corroborando os dados da literatura que referem que a centralidade das preocupações dos EEs se situa nas tarefas de preparação do ensino. ${ }^{25,26}$ 
Quadro 13 - Referências às dimensões de ensino nos relatórios de estágio dos EEs dos 3 anos letivos

\begin{tabular}{lccccccc}
\hline & Setor & \multicolumn{3}{c}{ Público (\%) } & \multicolumn{3}{c}{ Privado (\%) } \\
\cline { 3 - 7 } Dimensões & de & $\mathbf{2 0 0 7 / 0 8}$ & $\mathbf{2 0 0 9 / 1 0}$ & $\mathbf{2 0 1 1 / 1 2}$ & $\mathbf{2 0 0 7 / 0 8}$ & $\mathbf{2 0 0 9 / 1 0}$ & $\mathbf{2 0 1 1 / 1 2}$ \\
ensino & & & $\mathbf{4 4 , 4}$ & $\mathbf{2 6 , 6}$ & $\mathbf{4 0 , 0}$ & $\mathbf{4 0 , 0}$ & $\mathbf{2 6 , 6}$ \\
\hline Planeamento & $\mathbf{4 4 , 4}$ & $\mathbf{1 9 , 8}$ & $\mathbf{6 0 , 0}$ & $\mathbf{2 6 , 6}$ & $\mathbf{2 2 , 9}$ & $\mathbf{5 3 , 3}$ \\
Instrução & 11,1 & 13,5 & $\mathbf{2 6 , 6}$ & 6,7 & --- & 6,6 \\
Conteúdo & 11,1 & 16,9 & --- & 6,7 & --- & --- \\
Clima & 11,1 & 11,6 & 20,0 & 13,3 & 15,9 & 13,3 \\
Gestão & --- & --- & 20,0 & --- & --- & 6,6 \\
Avaliação & & & & & & \\
\hline
\end{tabular}

Neste ponto, a ordem inverte-se, isto é, a instrução passa a assumir o primeiro posto e o planeamento em segundo, sendo que as práticas pedagógicas podem estar na origem desta inversão. Pois, de acordo com Durand, ${ }^{27}$ estas evoluíram no sentido de promover o abandono de posições prescritivas; a capacidade de se descentralizar; a tomada de consciência da diversidade das práticas; a reflexão sobre o que é o acompanhamento e a orientação; a competência de análise das práticas; a capacidade de perceber o que é significativo e organizador da atividade dos estagiários e a matriz de técnicas de direção dos seminários semanais, de observação de aulas, entre outras.

A dimensão conteúdo junta-se ao planeamento nos estudantes do setor público. Na esfera das instruções, os relatórios de estágio destacam a orientação colaborativa do PC promovendo as práticas pedagógicas supervisionadas. A dimensão avaliação apresenta, com alguma surpresa, valores nulos ou modestos, sendo que apenas os EEs do setor público no ano 2011/12 lhe atribui um valor relevante. Valoriza-se a avaliação enquanto critério pedagógico para se julgar a realidade vivida, surgindo associada ao planeamento e concebida de forma integrada nas atividades de aprendizagem. Conteúdo e clima pautam-se por registo nulo ou muito baixo.

\section{CONCLUSÕES}

$\mathrm{Na}$ componente longitudinal (socialização antecipatória e alterações de conceções) é de salientar que:

- As experiências positivas de pré-socialização emergiram de forma semelhante em todos os estudantes, nomeadamente enquanto alunos de EF (relações interpessoais e possibilidade de praticar várias modalidades 
desportivas) e caraterísticas do professor que mais valorizaram (aspetos da personalidade/atitude como ser amigo, divertido, simpático);

- Não existiu similitude ao nível das experiências negativas; o autoritarismo do professor apareceu referido no setor público;

- O setor não se revelou fator diferenciador das conceções prévias acerca do "bom professor"; contudo, com o tempo, verificou-se um decréscimo da valorização da ética e a um acréscimo da dimensão técnica;

- Na dimensão intelectual foi a subcategoria conhecimento que recolheu o maior número de referências, facto que se acentuou no terceiro ano $\left(2^{\circ}\right.$ momento) e no ano de EP ( $3^{\circ}$ momento), sendo que a e formação contínua foi um elemento muito pouco valorizado;

- As técnicas de ensino mantiveram uma expressão elevada embora decrescente com o avançar do percurso formativo. Já a eficiência/qualidade revelou uma valorização crescente, denunciando uma acentuação do fator rendimento;

- Ao nível da dimensão ética os estudantes de ambos os setores valorizaram mais o bom senso/empatia e pedagogia aquando da entrada na FI;

- Ao longo do processo da FI registou-se maior tónica nas questões profissionais em detrimento das questões do saber estar.

- Na dimensão relacional as relações interpessoais assumiram a primazia, sendo que o trabalho em equipa apenas no terceiro momento surgiu com alguma expressão.

Em síntese, as experiências de socialização como aluno de EF encontraram reflexo na noção de "bom professor"; a conceção inicial foi-se transformando ao longo do percurso, nomeadamente com primazia dos aspetos de natureza técnica e um pouco do conhecimento, valorando os aspetos relativos à ética profissional em detrimento dos da ética pessoal.

A valoração excessiva de umas dimensões indicia que os estudantes possuem uma noção de competência restrita e não integrada. Por conseguinte, não obstante as valorizações se alterarem, persistiu uma noção de "competência" e não uma verdadeira conceção de 
"professor competente". ${ }^{28}$ As questões relacionadas com a inovação, atualização, empenhamento, autoridade/maturidade foram pouco valorizadas, denunciando distanciamento das necessidades das profissões na generalidade e mais ainda das profissões pedagógicas.

No que concerne à componente transversal ao longo do ciclo de cinco anos do estudo foi possível extrapolar que:

- Os EE atribuíram aos PCs uma multiplicidade de papéis, com apoio e orientação como mais valorizados em ambos os setores;

- As caraterísticas pessoais dos PCs mais valorizadas foram a amizade, a competência e a disponibilidade;

- O apoio pessoal (emocional e apreciativo) foi o mais valorado pelos EEs de ambos os setores;

- O planeamento e a instrução foram as ações pedagógicas dos PCs mais valoradas nos dois setores de ensino;

- Não se constatou relevância atribuída à dimensão avaliação.

Em suma, houve transformações das conceções dos estudantes ao longo da FI, mas não no sentido de conceções mais holísticas e integrativas acerca da "EF e Desporto" nem do "professor competente". As diferenças entre os estudantes do setor público e privado não foram relevantes. Cruzando as componentes, longitudinal e transversal, pode concluir-se que os EEs adotaram uma conceção de EF muito centrada nos aspetos de natureza técnica, perdendo progressivamente a conceção centrada em aspetos de natureza ética e relacional, o que pode ser comprometedor sobre qual o efetivo papel dos professores.

\section{REFERÊNCIAS}

${ }^{1}$ FLORES, A.; DAY, C. Contexts whish shape and reshape new teachers' identities: a multiperspective study. Teaching and Teacher Education, New York, v.1, n. 22, p. 219$232,2006$.

${ }^{2}$ ALBUQUERQUE, A.; BATISTA, P.; PINHEIRO, C. Étude de l'évolution des perspectives professionnelles des élèves d'éducation physique et sport pendant sa formation dans les secteurs public et privé : étude 1. In: BIENNALE DE L'ASSOCIATION POUR LA Conexões: revista da Faculdade de Educação Física da UNICAMP, Campinas, v. 11, n. 2, p. 127-147, abr./jun. 2013.144 ISSN: 1983-9030 
RECHERCHE SUR L'INTERVENTION EN SORT, 4., 9-12 mai 2006, Besançon. Programme scientifique... Besançon, 2006. p. 34.

${ }^{3}$ CRUM, B. Conventional thought and practice in physical education: problems of teaching and implications for change. Quest, Champaign, v.1, n. 45, p. 339-356, 1993.

${ }^{4}$ JOHNSON, N. et al. The induction of teachers: a major internship program. Journal of Teacher Education, Washington, n.144, p. 296-304, 1993.

${ }^{5}$ BENTO, J. O outro lado do desporto. Porto: Campo das Letras, 1995.

${ }^{6}$ DUBAR, C. A socialização: construção das identidades sociais e profissionais. Porto: Porto Editora, 1997.

${ }^{7}$ SHULMAM, L. S. The wisdom of practice: essays on teaching and learning to teach. San Francisco: Jossey-Bass, 2004.

${ }^{8}$ TARDIF, M. Saberes docentes e formação profissional. 12. ed. Petropolis: Vozes, 2012.

${ }^{9}$ ALBUQUERQUE, A.; GRAÇA, A.; JANUÁRIO, C. A supervisão pedagógica em Educação Física: a perspetiva do orientador de estágio. Lisboa: Livros Horizonte, 2005.

${ }^{10}$ LORTIE, D. Schoolteacher: a sociological study. London: University of Chicago, 1975.

${ }^{11}$ ZEICHNER, K.; TABACHNICK, B. Are the effects of university teacher education washed out by school experiences? Journal of Teacher Education, Washington, v.32, p. 7-11, 1981.

${ }^{12}$ CALDERHEAD, J. The contribution of field experiences to student primary teacher's professional learning. Research in Education, Washington, v.1, n. 40, p. 33-39, 1988.

${ }^{13} \mathrm{SCHON}$, D. Educando o profissional reflexivo: um novo design para o ensino e a aprendizagem. Porto Alegre: Artmed, 2000. 
${ }^{14}$ BATISTA, P.; MATOS, Z.; PINHEIRO, C. Experiências de pré-socialização na profissão de professor de Educação Física. Implicações para as experiências da formação inicial. In: CONGRESSO DE CIÊNCIAS DO DESPORTO E EDUCAÇÃO FÍSICA DOS PAÍSES DE LÍNGUA PORTUGUESA, 10., 2004, Porto. Anais ... . Porto: FCDEF, 2004.

${ }^{15}$ CARREIRO DA COSTA, F. et al. Formação de professores em Educação Física. conceções, investigação, prática. Lisboa: Cruz Quebrada: Serviço de Edições F.M.H., 1996.

${ }^{16}$ FORMOSINHO, J. Formação de professores: aprendizagem profissional e ação docente. Porto: Porto Editora, 2009.

${ }^{17}$ GOLD, Y. Beginning teacher support. attribution, mentoring and induction. In: JOHN SIKULA; T. BUTTERY; E. GUYTON (Ed.). Handboock of reserch on teacher education. $2^{\text {nd }}$ ed. New York: MacMilan, 1996. p. 548-594.

${ }^{18}$ JANUÁRIO, C. Do pensamento do professor à sala de aula. Coimbra: Livraria Almedina, 1996.

${ }^{19}$ BARDIN, L. Análise de conteúdo. Lisboa: Edições 70, 2008.

${ }^{20}$ MEINBERG, E. Ciência do Desporto: balanço e perspetivas. In: BENTO, J.; MARQUES, A. (Ed.). As ciências do desporto e a prática desportiva: desporto na escola. Porto: FCDEF, 1991. p. 41-51.

${ }^{21}$ ALARCÃO, I.; ROLDÃO, M. Supervisão: um contexto de desenvolvimento dos professores. Mangualde : Edições Pedagogo, 2008.

${ }^{22}$ VANDERCLEYEN, F. et al. Construction d'une identité professionnelle en tension chez des enseignants-stagiaires en éducation physique. In : CARLIER, G.; BORGES, C.; DELENS, C. Identité professionnelle en éducation physique. Louvain : Universitaires de Louvain, 2012. 
${ }^{23}$ ANDERSON, E.; SHANNON, A. Towards a conceptualization of mentoring. Journal of Teacher Education, Washington, v. 39, n.1, p. 38-42, 1988.

${ }^{24}$ CALDERHEAD, J.; SHORROCK, S. Understanding teacher education: case studies in the professional development of beginning teacher. Bristol: The Taylor \& Francis e-Library, 2005.

${ }^{25}$ GRIFFIN, G. A. Student teaching and the commonplaces of schooling. Texas: ERIC Cleringhouse, 1983.

${ }^{26}$ GROSSMAN, P.; MCDONALD, M. Back to the future: directions for research in teaching and teacher education. American Educational Research Journal, Washington, v. 45, n.1, p. 184-205, 2008.

${ }^{27}$ DURAND, M. Interview de Marc Durand. Montpellier: Académie de Montpellier, 2002.

${ }^{28}$ HAGER, P. Know-how and workplace practical judgment. Journal of Philosophy of Education, London, v. 34, n. 2, p. 281-296, 2000.

Recebido em: 08 mar. 2013 Aceito em: 16 maio 2013

Contato: Paula Fazendeiro Batista paulabatista@fade.up.pt 